\title{
NUEVA LECTURA DE LAS OBRAS DE MISERICORDIA DE MARIANO BENLLIURE
}

\author{
NEW CONSIDERATION ON THE WORKS OF MERCY \\ OF MARIANO BENLLIURE
}

\author{
RAFAEL ÁNGEL GARCÍA-LOZANO*
}

Resumen: Abordamos en este trabajo una nueva perspectiva de análisis de las Obras de misericordia realizadas por el renombrado escultor español Mariano Benlliure. El artista realizó varias series de los originales en diversos materiales, las cuales se encuentran diseminadas por España. En virtud de nuestro estudio hemos detectado varios problemas en la identificación y ejecución de algunos relieves de las series, que a priori eran idénticos, debido a ciertas vicisitudes históricas, especialmente elocuentes en el análisis comparativo entre las piezas del mausoleo de la II Vizcondesa de Termens emplazado en Cabra (Córdoba) y el paso Redención de la Semana Santa de Zamora, así como en las obras existentes en algunos museos y colecciones particulares. Ello nos ha permitido realizar una nueva lectura y profundización en la interpretación de estas piezas, que nos lleva a descubrir y proponer algunas consideraciones que cuestionan ciertos aspectos sostenidos hasta ahora.

Palabras Clave: Mariano Benlliure, II Vizcondesa de Termens, Obras de misericordia, relieves, mausoleo-monumento funerario.

ABSTRACT: In this work there is a new approach to the analysis of the Works of mercy by the renowned Spanish sculptor Mariano Benlliure. The artist produced different series of the originals in various materials, which are scattered across Spain. In our study we have detected several inaccuracies in the identification and execution of some reliefs of these series, which a priori were identical. Such inaccuracies are due to certain historical difficulties. This is especially evident in the comparative study of the pieces in the mausoleum of the II vizcountess de Termens, located in the town of Cabra in Cordoba, in Redemption, a sculpture group of Easter in Zamora, as well as existing works in many museums and private collections. This has allowed us to make a new reading in the interpretation of these pieces, which leads us to discover and propose some considerations which question certain ideas maintained until now.

Keywords: Mariano Benlliure, II Vizcountess de Termens, Works of mercy, reliefs, Mausoleum-funerary monument.

Recibido: 03.05.2020. Aceptado: 13.01.2021.

* Doctor en Historia del Arte. Académico de la Universidad Pontificia de Salamanca, Salamanca, España. Correo electrónico: ragarcialo@upsa.es. Orcid: http://orcid.org/0000-0003-4913-7019. 
$\mathrm{M}$ ariano Benlliure Gil (Grao de Valencia 1862-Madrid 1947) es para la historia del arte español el más importante escultor, a caballo entre los siglos XIX y XX, tanto por la perfección de su técnica como por lo prolífico y popular de su producción artística. Insertado en el estricto academicismo, el conjunto de su obra es de carácter realista incluso en extremo, hasta el punto de, como sostiene Portela, haber hecho suya la tarea de "liberar a la escultura española de los aspectos idealistas que persistían desde el Romanticismo" (Sambricio et al., 1989, p. 134). A pesar de que trabajó hasta poco antes de su muerte, su producción continuó siendo íntegramente ochocentista. Probablemente esta circunstancia y el sentido narrativo y minucioso de su escultura son las razones que explican el abultadísimo volumen de su obra, cuyas realizaciones se extienden por Europa (España, Portugal, Francia y Grecia), Filipinas, Estados Unidos y países latinoamericanos como Argentina (Buenos Aires, Paraná), Colombia (Bogotá), Cuba (La Habana), México (Coatepec), Panamá (Panamá), Perú (Lima) y Chile (Monumentos al general Bulnes en Santiago de Chile y en Punta Arenas) (Dirección General, 2013, p. 337). Sus esculturas abarcan géneros como el monumento conmemorativo, las temáticas gitana y taurina, el retrato y las representaciones infantiles. Tal cantidad de obra, tanto pública como privada, dejó espacio para la temática religiosa, fundamentalmente funeraria e imágenes de Semana Santa (Enseñat, 2018, pp. 45-46), que, por su propio carácter, condensa los valores más excelsos y característicos del autor.

Precisamente las Obras de misericordia de Benlliure constituyen un conjunto que, por su incorporación a sendos grupos escultóricos, participa de ambos subgéneros de temática religiosa. Estos relieves forman parte del mausoleo de la II Vizcondesa de Termens, en la localidad andaluza de Cabra, y del paso Redención, uno de los grupos de la imaginería religiosa más relevantes de Benlliure, localizado en Zamora, al noroeste peninsular. Y asimismo se halla también disperso en piezas sueltas en algunos museos y en colecciones particulares. El conjunto de las Obras de misericordia, que podría ser tildado de carácter secundario juzgado simplemente por formar parte de grupos escultóricos de mayor entidad, adquiere por sí mismo una relevancia notable por su envergadura. No obstante, tal dimensionamiento parece hallarse en estado expectante. Centrados en el análisis de estas obras escultóricas, nuestro proceso de investigación ha acabado sacando a la luz, no sin sorpresa, que ambas series no son exactamente idénticas como hasta ahora se presuponía. En este trabajo desentrañamos los elementos propios 
de cada una y los vínculos existentes entre ellas, desarrollando una lectura comparativa que se torna, sin duda, decisiva. Aportamos algunas claves que permiten ofrecer un nuevo acercamiento a las Obras de misericordia, y lo hacemos fundamentalmente a partir del planteamiento de ciertas puntualizaciones formales y sobre todo de la puesta en cuestión de determinadas afirmaciones sostenidas hasta ahora, proponiendo incluso algunas hipótesis ante los vacíos que nos ha dejado la historia y la prácticamente nula documentación conservada ${ }^{1}$.

\section{EL MAUSOLEO DE LA II VIZCONDESA DE TERMENS}

Entroncado en contexto histórico español consecuente al período isabelino, y en el marco de la producción funeraria de Mariano Benlliure, el mausoleo de la II Vizcondesa de Termens constituye uno de los referentes de este género en el conjunto de su obra. Quizás a ello haya contribuido su situación de alejamiento geográfico de los núcleos artísticos y de poder del país, suponiendo además un referente en el contexto local en que fue levantado. Así, construido en el entonces recién inaugurado cementerio de San José de la localidad cordobesa de Cabra (Guzmán, 2002, pp. 102-106), no solo ostentó una significatividad extraordinaria en ese camposanto, sino que ocupó además un lugar de relevancia en el imaginario colectivo de sus ciudadanos.

La promotora del monumento funerario fue María del Carmen Giménez Flores (Cabra, 1867-Cabra, 1938). Había nacido de condición humilde en la ciudad egabrense y siendo aún adolescente marchó a servir a Madrid a la residencia de Juan de Ulloa y Valera, diputado en Cortes por la ciudad cordobesa (Miranda, 2011). En virtud de su notoria belleza, y en el seno de los círculos cortesanos en los que se movía su distinguido patrón, acabó llamando la atención del Infante don Antonio de Orlans y Borbón, primo y esposo de la Infanta doña María Eulalia de Borbón, a la sazón hermana del rey Alfonso XII (Guzmán, 2010, pp. 20 ss). Tras los primeros encuentros y escarceos, a partir de 1888 pasó a ser su amante, y de ahí el apelativo de "La Infantona" con el que fue conocida entre la alta sociedad madri-

\footnotetext{
${ }^{1}$ Agradecemos la generosidad en las informaciones de Lucrecia Enseñat Benlliure, Vicepresidenta de la Fundación Mariano Benlliure y biznieta del escultor, y la colaboración de José Andrés Casquero Fernández, así como las facilidades brindadas por Javier García Peiro, de la Casa-Museo Benlliure. Ayuntamiento de Valencia, el colegio de Educación Especial Niño Jesús-Fundación Termens en la persona de sor Emilia Arjona Carrillo y las fotografías de José Lopera Muñoz.
} 
leña. Como una de las dádivas recibidas de esa relación que se extendió durante casi treinta años, a partir de 1910 ostentó título nobiliario después de reivindicarlo haciendo valer su apellido Brito, el primero de su abuela materna. Tanto su amante como ella misma pronto lo vincularon con el de Gregorio de Brito y Carvahlo, a quien Felipe IV le había concedido este título en 1646, distinción que no había sido reclamada desde su muerte. Una vez se hizo poseedora de este reconocimiento, para hacer ostentación de la condición alcanzada en su ciudad natal, la II Vizcondesa se hizo construir un mausoleo diseñado por el más reputado escultor del país en esa época. Así, Mariano Benlliure fue el elegido para plantear las trazas y efectuar los trabajos escultóricos, mientras que la cuestión estrictamente constructiva correspondió al arquitecto Manuel Arévalo. Encargadas en 1908, las obras se llevaron a cabo seis años más tarde, entre julio y noviembre de 1914 (Guzmán, 2002, p. 45).

El monumento funerario formaba un magnifico conjunto integrado por una capilla y un mausoleo escalonado con tres sepulcros labrados en mármol de Carrara. Este último representa las figuras yacentes de la Vizcondesa, elevada en un plano superior, y las de sus padres flanqueándola en un plano inferior, así como una figura humana en pie que simboliza el alma de la comitente. El conjunto escultórico se emplazaba ante la puerta de una pequeña capilla de planta rectangular que integraba a la vez las funciones de espacio sacro y acceso a los enterramientos. El recinto adoptaba elementos escultóricos realizados en bronce y otros labrados en mármol de Chercos y Alicante al exterior, y en el interior destacaban algunas piezas trabajadas en mármol de Carrara como las efigies de San Juan, San José y Dios Padre (Quevedo, 1947, p. 310), así como una extraordinaria imagen de la Virgen del Carmen, advocación mariana elegida en virtud del nombre de pila de la propietaria. Sentada en majestad, la Virgen sostiene al niño Jesús en pie, al que muestra y custodia con maternal mirada, y en cuya mano derecha porta un escapulario carmelita metálico. El conjunto descansa sobre una nube y dos serafines que custodian el sagrario, formando un único bloque apoyado sobre un altar de mármol de Chercos sostenido por dos ramos de palma labrados (Quevedo, 1947, p. 309). Sobresalen también las piezas realizadas en bronce, obra del mismo autor, que se concretan en las dos puertas del recinto ornadas con figuras angélicas, sendos medallones que representan a los hermanos de la promotora instalados en el friso y un relieve de la Anunciación emplazado en la fachada posterior de la capilla. Asimismo, en el friso fueron instalados ocho relieves fundidos en bronce patinado en negro (Guzmán, 2002, p. 62) que representan las Obras de 
misericordia, acomodados a los ocho espacios destinados para ello en dos tamaños diferentes conforme se ubicaran en los testeros o los costados de la capilla. Las piezas se fundieron en marzo de 1914 (Quevedo, 1947, p. 308), como también se documenta en los registros de la Fundición Codina, según se nos confirmó desde la Fundación Mariano Benlliure (Lucrecia Enseñat. Comunicación personal, 28 de enero, 2017) (Fig. 1).

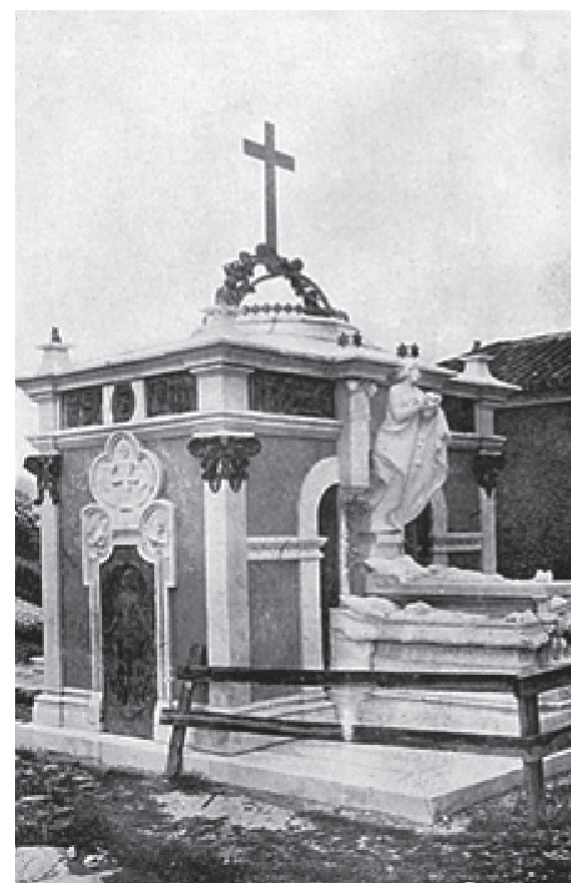

Figura 1. Mausoleo en el cementerio de Cabra. Archivo Fundación Mariano Benlliure, por cortesía de Salvador Guzmán.

Solo un año después de la finalización del conjunto funerario, y como consecuencia de la realización de un informe pericial que avalase el resultado de la obra, la propietaria encargó al arquitecto Enrique Daverio una serie de mejoras en el panteón con el fin de enriquecerlo aún más, si bien algunas de sus propuestas quedaron finalmente sin ejecutar (Guzmán, 2002, pp. 121 ss). Algunos años más tarde la Vizcondesa decidió fundar en Cabra una institución encargada de la formación de niños bajo su patronazgo, promoviendo la construcción de un grupo escolar que fue proyectado por el 
propio Daverio en 1930. Conforme a la fe religiosa de la comitente y al tipo de formación que había ideado para la institución, la Vizcondesa dispuso que el centro debía contar con una capilla en la que, además, había de existir una estancia funeraria donde ella pudiera reposar bajo la custodia de las religiosas en quienes confiaría la gestión de la Fundación y no en la soledad del camposanto. Así pues, la Vizcondesa dispuso el desmantelamiento del mausoleo y el traslado de los elementos escultóricos ejecutados por Mariano Benlliure al colegio Fundación Termens en junio de 1931, permaneciendo en el cementerio únicamente la capilla desprovista de la decoración que pudo ser trasladada (Guzmán, 2002, p. 135). Desde entonces el mausoleo, el altar y otros elementos decorativos permanecen reordenados en la capilla funeraria y el presbiterio del oratorio del centro escolar (Fig. 2).

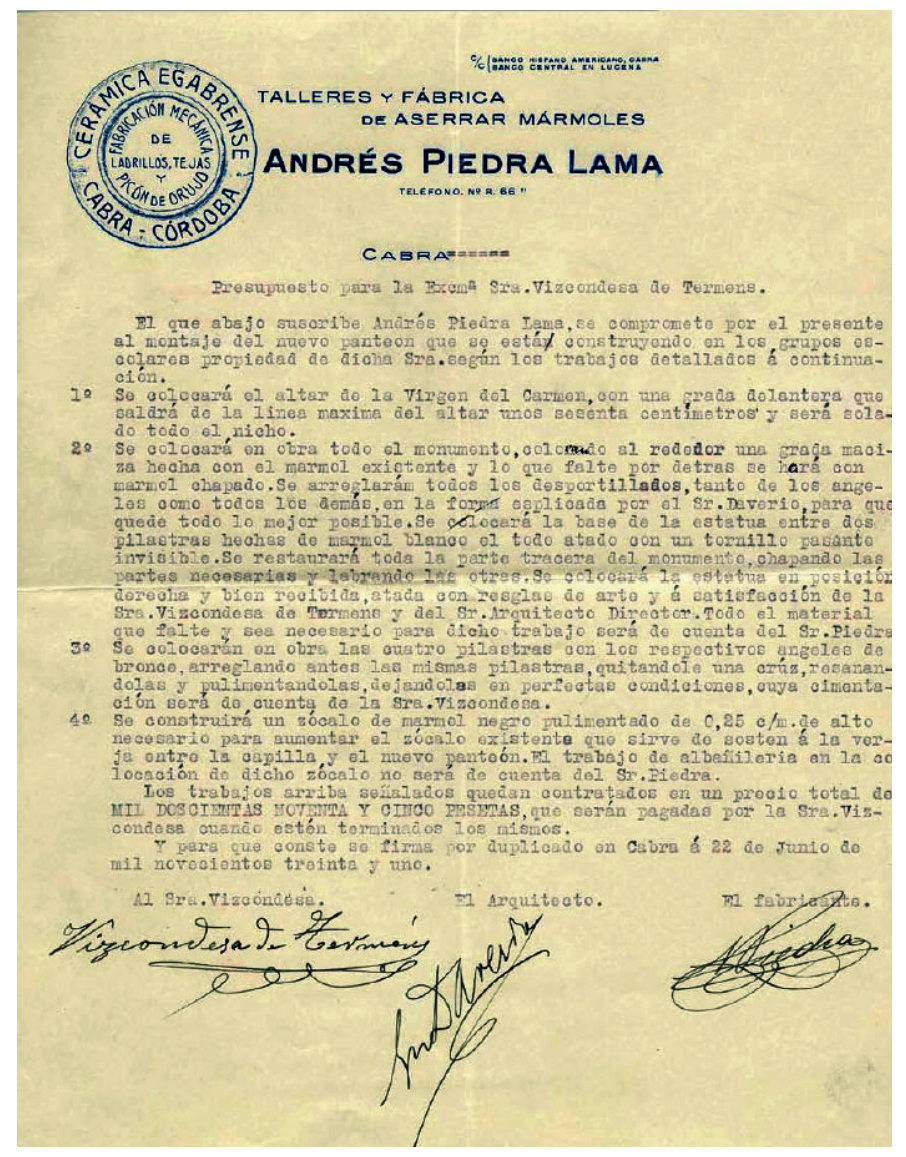

Figura 2. Biblioteca de Cabra. Fondo local. Sección Vizcondesa de Termens. s.n. 
El traslado de estas piezas a su definitivo emplazamiento garantizó el cumplimiento de la voluntad de la propietaria en cuanto a la custodia de sus restos mortales y los de sus padres bajo la guarda de las Hijas de la Caridad. También el vínculo existente entre la Fundación Termens y su promotora quedó más estrechamente cerrado al evidenciar así su permanente presencia en la obra caritativa. La decisión del traslado afectó positivamente a la conservación del mausoleo, pues el hecho de encontrarse a cubierto lo protege de las agresiones climáticas y de otras consecuentes de la lejanía de su anterior emplazamiento respecto del núcleo poblado. A pesar de estas circunstancias, la decisión del traslado conllevó la mutilación del conjunto, pues el panteón se encuentra desmembrado de sus componentes arquitectónicos originales. Asimismo, la adecuación de los elementos escultóricos a su nueva ubicación fracturó de algún modo su unidad, dado que, mientras algunas piezas quedaron integradas en la estancia funeraria de la capilla del centro como un todo, otras pasaron a incorporarse reordenadas en el presbiterio del templo, alterando al menos la vocación de servicio a una finalidad inmediatamente mortuoria (Fig. 3).

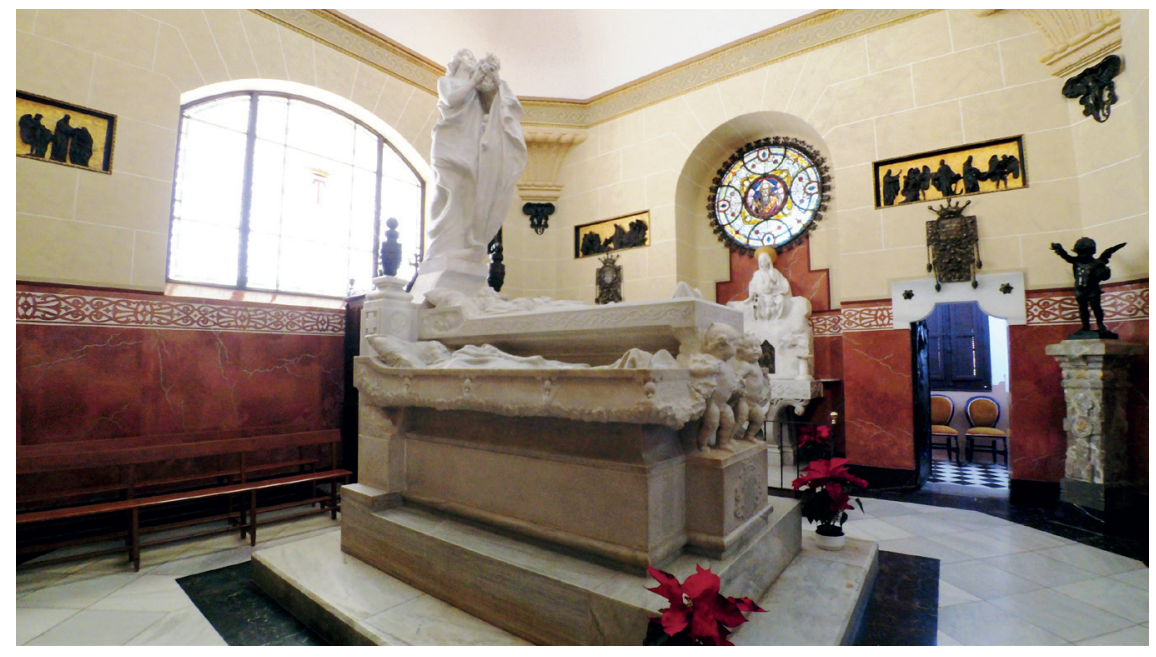

Figura 3. Capilla de la Fundación Termens.

Foto: José Lopera Muñoz. 


\section{LAS OBRAS DE MISERICORDIA EN LOS MUSEOS DE VALENCIA, CREVILLENTE Y COLECCIONES PARTICULARES}

Las circunstancias aludidas nos sitúan con mayor perspectiva ante el mausoleo de la II Vizcondesa de Termens tal como se encuentra en la actualidad. Ciertamente los datos aportados hasta ahora sobre el panteón son sobradamente conocidos gracias a los trabajos de Salvador Guzmán Moral. Quizá la relevancia y categoría de su escultor y proyectista, unidas a otras circunstancias de tipo personal, motivaron su estudio por parte de este autor como objeto de su tesis doctoral, publicada posteriormente como un volumen divulgativo convertido en referente para el conocimiento del panteón e incluso de su promotora, cuya biografía ha sido también afrontada por Guzmán en trabajos posteriores. Sin embargo, las aportaciones de esa investigación requieren de una nueva reconsideración, al menos en lo relativo a las Obras de misericordia.

Guzmán dedica en su libro un apartado a la descripción de los relieves que representan las Obras de misericordia y en el que ofrece un análisis de los aspectos iconográficos/iconológicos [sic.] de los mismos (2002, pp. 1026). Además de referirse a ellos en otros lugares del volumen, en este apartado fueron estudiados tal como se encuentran actualmente en la estancia funeraria de la Fundación Termens, además de exponer varias referencias relativas a estos en su emplazamiento original. Sin embargo, podemos asegurar que en la mera lectura de los relieves el autor ha incurrido en algunas inexactitudes. En efecto, su relato comienza con la enumeración de las Obras de misericordia, pero antes de pasar a la descripción de los relieves, Guzmán propone ciertas afirmaciones a partir de la incorrecta identificación de algunas piezas con su correspondiente obra de misericordia, incurriendo, pues, en algunos errores que se arrastran posteriormente en el texto.

Para tratar de dar respuesta a esta cuestión hemos considerado establecer una comparativa entre los relieves tal como se conservan en su actual emplazamiento en la Fundación Termens y la descripción que de ellos ofrece Guzmán en su publicación. Para ello nos hemos auxiliado del estudio que hemos realizado sobre distintas reproducciones existentes de estos mismos relieves. Como el propio Guzmán reseña al final del mencionado apartado, existen bien modelos originarios de los relieves o bien copias posteriores, al fin y al cabo reproducciones, realizadas en otros materiales, 
bronce, cerámica e incluso madera (2002, p. 106). En efecto, se conservan tres paneles en el Museo Mariano Benlliure de Crevillente (Alicante) que representan 'Dar posada al peregrino', 'Vestir al desnudo' y 'Dar de comer al hambriento, los dos primeros realizados en escayola policromada y el último en cerámica policromada y vidriada. Contamos también con los bronces 'Dar posada al peregrino' y 'Dar de comer al hambriento' en una colección particular y originariamente procedentes de la casa-estudio de Benlliure en la madrileña calle Abascal. Asimismo, en manos de otro coleccionista particular se encuentra 'Dar de beber al sediento', relieve realizado en cerámica policromada. Otra pieza en manos particulares que reproduce la obra de misericordia inexactamente denominada 'Visitar a los enfermos' fue realizada en escayola patinada y salió a subasta en la firma Segre en octubre de 2016, aunque no fue vendida (Lucrecia Enseñat. Comunicación personal, 24 de enero, 2017). Finalmente, existen siete relieves con las Obras de misericordia realizados en madera de caoba en la mesa procesional del paso Redención propiedad de la Cofradía de Jesús Nazareno de Zamora y que se custodia en el Museo de Semana Santa de esa ciudad (García-Lozano, 2008, p. 109). Estos últimos, aunque pertenecen a la gubia del más directo colaborador de Mariano Benlliure, Juan García Taléns, presentan fielmente el repertorio íntegro de las Obras de misericordia de su maestro y, por lo tanto, ofrecen la alternativa más completa para efectuar la comparativa planteada.

En este punto podemos establecer una rigurosa comparación de todas las piezas y realizar una lectura integrada y paralela de todas ellas. Y, a partir de esta, adoptar elementos de juicio que, como veremos, pondrán en cuestión los criterios de agrupamiento seguidos en la distribución de los relieves tras su traslado a la capilla de la Fundación Termens. De ahí se han seguido ciertas conclusiones que, por un lado, cuestionan algunas afirmaciones de Guzmán, por otro, presentan algunos datos novedosos y plantean algunas hipótesis a los vacíos dejados sin resolver por este autor.

\section{EL PASO REDENCIÓN}

Seguramente el más completo repertorio iconográfico de las Obras de misericordia de Mariano Benlliure nos lo ofrecen los relieves reproducidos en la mesa procesional del paso realizado para Zamora denominado por el 
propio escultor El Redentor camino del Gólgota, conocido como Redención. La cofradía de Jesús Nazareno de Zamora, vulgo Congregación, inició en 1926 los contactos con el escultor valenciano para sustituir su nazareno titular y contar en la imaginería procesional de la ciudad con un nuevo paso de su autoría. La hermandad habría adoptado desde su fundación en 1651 una imagen barroca de vestir que fue sustituida en 1802 por una nueva talla de Justo Fernández a la que este ambicioso proyecto vendría a reemplazar (Casquero, 2009, p. 9). Ya en 1879 Mariano Benlliure había realizado para la Semana Santa zamorana, cuando contaba solamente dieciséis años de edad, el que fue el primer gran encargo de su trayectoria, el paso denominado El Descendido. Este había sido posible gracias a su permanencia en la ciudad, junto con su padre y su hermano Blas, para acometer las obras de reforma y decoración del Palacio de los Valencia a instancias de Federico Cantero Seirullo, ingeniero director de la línea ferroviaria Medina del Campo-Zamora (García-Lozano, 2010, p. 41). Fracasadas las negociaciones de la Cofradía del Santo Entierro con el imaginero local Ramón Álvarez Prieto (1825-1889) para la elaboración de un nuevo paso, el ingeniero avaló ante la hermandad la valía y oficio del adolescente Mariano Benlliure, consiguiendo así el encargo de la obra (Casquero, 2004, p. 6).

Así, 47 años después del estreno de su primer paso, la gubia de Mariano Benlliure fue reclamada de nuevo en Zamora, en este caso de la mano de la cofradía de Jesús Nazareno. Con la aceptación del escultor se inició un largo proceso que concluyó cinco años más tarde, debido a las desavenencias surgidas entre la cofradía y la Junta de Fomento -órgano entonces aglutinante de las hermandades de Semana Santa de la ciudad- en razón de la falta de liquidez económica para correr con los gastos de las tres imágenes y la mesa procesional (Casquero, 2012, p. 328). Por esta razón, y aunque Mariano Benlliure almacenaba en su estudio las imágenes talladas ya desde 1928 (Fernández-Prieto y García, 1997, p. 49), se demoró el tiempo de entrega hasta que finalmente tuvo lugar la bendición del conjunto el 31 de marzo de 1931.

El acto de bendición se celebró en la iglesia del exconvento de Santa Marina, ya desamortizada y en uso como sede del Museo Provincial de Bellas Artes (Casquero, 2003, s/p). Este dato, que no es baladí, pone de manifiesto que el grupo escultórico y su mesa fueron efectivamente tallados para su salida en procesión y, por lo tanto, como conjunto para el culto público. 
Pero revela asimismo que fue singularmente concebido por su autor también como una suerte de escultura pública monumental (Casquero, 2012, p. 329). Efectivamente, parece que el propio Mariano Benlliure deseaba este paso más para la admiración en un contexto museístico que devocional. Tanto es así que el grupo permaneció expuesto en el Museo Provincial de Bellas Artes hasta que dos años más tarde hubo de pasar a la panera-almacén de la cofradía por causas de fuerza mayor (García-Lozano, 2011, pp. 84-7). Además, las informaciones publicadas en la prensa nacional parecen confirmar esta voluntad expositiva del escultor respecto del paso, si bien concretadas en una ubicación alternativa. En efecto, al hacerse eco de la presentación en sociedad del grupo escultórico en el estudio de Mariano Benlliure en la capital madrileña ante el Nuncio de Su Santidad, el Conde de Romanones (Casquero, 2009, p. 23) y el propio Alfonso XIII (Fernández-Prieto y García, 1997, p. 51), el diario $A B C$ recogió textualmente que "este paso procesional habrá de ser emplazado en una de las naves de la catedral de Zamora, a manera de monumento permanente" (Méndez Casal, 1931, p. 17).

El paso está formado por tres imágenes talladas en tamaño natural y la mesa que las contiene. La imagen de Jesús cargando con la cruz está trabajada en madera de tilo de Cuba, y ostenta el protagonismo del conjunto, ocupando su lugar central y preponderante. Cristo asido a la cruz con el brazo derecho eleva la mirada al cielo sin mostrar signos de sufrimiento, manifestando, por el contrario, su unidad y complicidad con el Padre en este trance. La imagen de Simón de Cirene, tallada en madera de caoba, ayuda a Jesús a portar la cruz, sosteniendo la parte central del stipes con ambas manos, mientras sugiere una mirada intensa hacia el reo. Humillada en el suelo cuerpo a tierra y detrás de Jesucristo aparece María Magdalena, concentrando calladamente el dolor de la escena. Tallada esta última en madera de caoba de Cuba, las tres imágenes fueron levemente patinadas por Mariano Benlliure dejando claramente entrever la madera (Casquero, 2012, p. 328) (Fig. 4). 


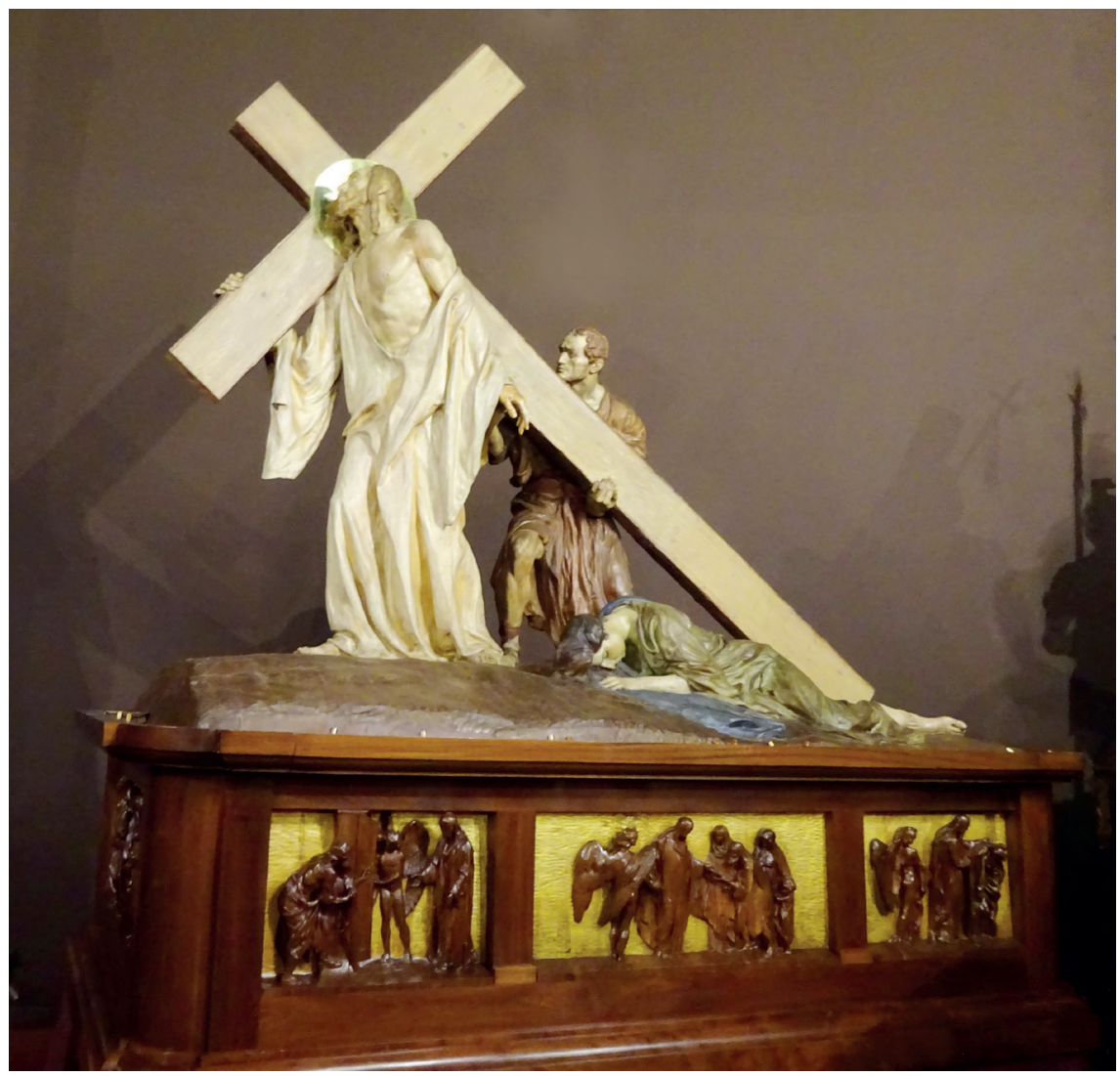

Figura 4. Redención. Mariano Benlliure.

Foto: Rafael Ángel García-Lozano.

La mesa sobre la que se disponen las imágenes fue trabajada en madera de caoba por el taller de Mariano Benlliure, incorporando discretamente líneas rectas y planas quizá cercanas al Art Decó en boga en las artes decorativas durante las fechas de su creación. Incluye la representación en altorrelieve de las siete Obras de misericordia corporales y las tres virtudes teologales, dispuestas en ocho paños en los cuatro frentes de la mesa y talladas por García Taléns (Casquero, 2009, p. 27). Junto con Mariano Rubio, este fue uno de los más relevantes miembros del taller de Benlliure, de quien no solo fue discípulo y colaborador, sino también amigo personal. Con el paso del tiempo acabó produciendo de forma independiente un interesante elenco escultórico e imaginero de firma propia. Como hemos señalado, los modelos originales de estos relieves habían sido realizados 
tres lustros antes por el propio Mariano Benlliure, y seguramente este consideró su inclusión en la mesa de Redención no solo por abordar una temática en plena consonancia con la representación del paso, sino también para enfatizar la condición de pedestal que indudablemente tiene la mesa, contribuyendo así a intensificar la vocación de escultura monumental del conjunto. A pesar de que el profesor Portela asegurase en su día que Mariano Benlliure fue un escultor "poco dotado para la imaginería religiosa" (Sambricio et al., 1989, p. 134), desde luego la calidad de su aportación a la Semana Santa zamorana es incuestionable. Más aún teniendo en cuenta que precisamente los grupos El Descendido y Redención fueron obras salidas íntegramente de sus manos y nunca trabajos del taller, tal como asegura Lucrecia Enseñat Benlliure (García, 2014, p. 28), con la excepción mencionada de las Obras de misericordia.

\section{RECONSIDERACIÓN DE LAS OBRAS DE MISERICORDIA}

La tarea de identificación y estudio de los relieves y su disposición originaria en el friso del mausoleo de la II Vizcondesa de Termens habría sido sencilla de haberse conservado el proyecto u otra documentación relativa a este monumento funerario o, cuando menos, a sus elementos escultóricos. Sin embargo, desafortunadamente no es así (Lucrecia Enseñat. Comunicación personal, 9 de febrero, 2017). Las fotografías que de este se conservan no permiten realizar con todas las garantías esta pretensión. No obstante, en buena lógica y según el testimonio autorizado de Lucrecia Enseñat, Mariano Benlliure habría realizado estudios a lápiz o tinta de las composiciones de cada una de las Obras de misericordia y, tras el proceso de estudio, pasaría directamente al modelado en barro. En efecto, precisamente sobre esta temática se conservan unos apuntes trazados sobre una hoja de cuaderno conservado en el archivo de la Casa-Museo Benlliure de Valencia, convirtiéndose en el testimonio documental más cercano a los relieves $^{2}$ (Fig. 5). Otros originales de esta serie, de haber existido, debieron sufrir quizá las consecuencias del desmantelamiento de la casa-estudio del escultor en la madrileña calle Abascal, de modo que no contamos con ellos (Lucrecia Enseñat. Comunicación personal, 9 de febrero, 2017).

\footnotetext{
${ }^{2}$ Apunte de Mariano Benlliure sobre las Obras de misericordia realizado en tinta sobre papel. $187 \mathrm{x}$ $148 \mathrm{~mm}$. Casa-Museo Benlliure. Ayuntamiento de Valencia. BEN/06/0332.
} 


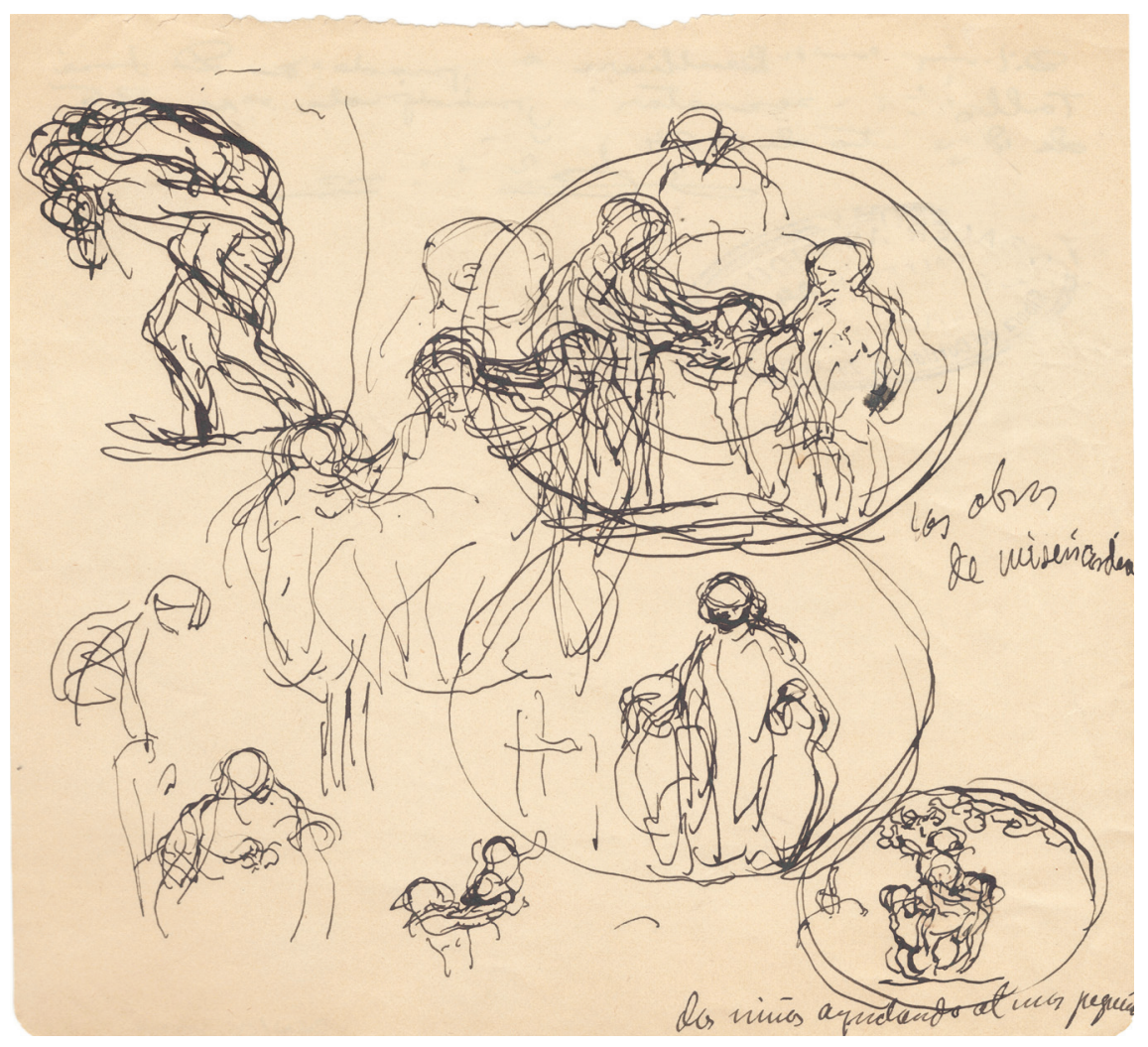

Figura 5. Apunte sobre las Obras de misericordia. Mariano Benlliure. Tinta sobre papel. 187 x 148 mm. Foto: Casa-Museo Benlliure. Ayuntamiento de Valencia.

A tenor de lo señalado más arriba, recordemos que la disposición de los relieves en la estancia funeraria de la Fundación Termens no reproduce la de su anterior emplazamiento en el friso de la capilla del camposanto egabrense, de modo que las obras distribuidas originalmente en ocho paneles en el friso del panteón pasaron a agruparse en seis paneles en su actual ubicación, disposición a partir de la cual Guzmán realizó su investigación. Este traslado implicó la reorganización de las escenas para adecuarlas a los tres muros de la nueva estancia, quizá sin otro criterio que el de adaptar el programa iconográfico a las nuevas posibilidades espaciales, lo cual supuso la disociación de algunas piezas y el agrupamiento de otras. Más aún, quizá, podría ser que este hecho hubiera conllevado incluso la pérdida de una de ellas, aunque esto no parece verosímil. En cualquier caso, recurrimos ahora a establecer una comparativa de estos relieves con los restantes conservados de las Obras de misericordia, principalmente los de Redención, que incorporan el programa en su integridad. 
Así, los relieves que representan 'Visitar a los presos'3 y 'Enterrar a los muertos', que originalmente ocuparon dos tramos cortos del friso de la capilla del cementerio (costados), fueron integrados en la Fundación Termens en un único panel, como si correspondieran a uno de los tramos largos del friso (testero). Además, insertaron entre ambos la representación de la virtud teologal 'Esperanza' (Fig. 6). Asimismo, el panel que representa 'Dar de comer al hambriento', proveniente de un tramo largo, incorporó además la figura de la virtud teologal 'Caridad' y un fragmento correspondiente al relieve 'Visitar a los enfermos'. Asimismo, el resto del relieve que representa 'Visitar a los enfermos', originalmente instalado también en un tramo largo, incorporó en su nueva estancia la virtud teologal ' $\mathrm{Fe}$ ', conformando también un panel de longitud mayor (Fig. 7). Por su parte, los relieves que originalmente se encontraban en los dos tramos cortos restantes, 'Dar posada al peregrino' y 'Vestir al desnudo', y uno más que ocupaba un tramo largo, 'Dar de beber al sediento', se trasladaron respetando su ordenamiento originario.
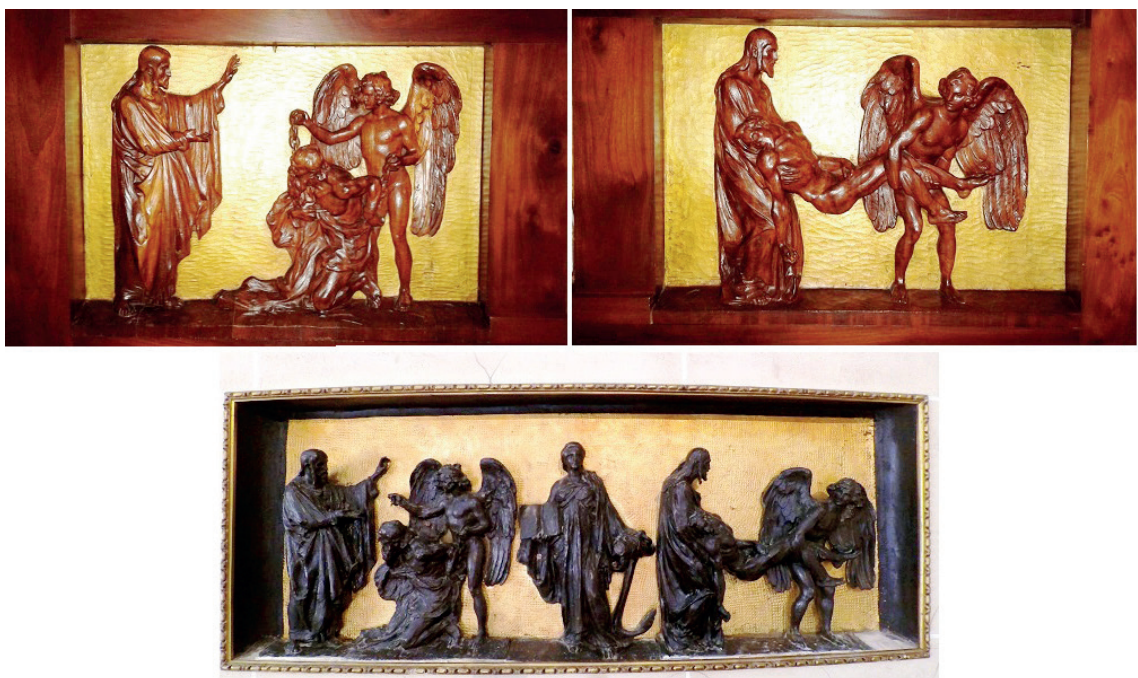

Figura 6. 'Visitar a los presos'. Redención. Foto: Rafael Ángel García-Lozano. I 'Enterrar a los muertos'. Redención. Foto: Rafael Ángel García-Lozano. / 'Visitar a los presos', 'Esperanza' y 'Enterrar a los muertos.' Relieves en la Fundación Termens. Foto: José Lopera Muñoz.

\footnotetext{
${ }^{3}$ Aunque algunas denominaciones refieren esta obra de misericordia como 'Redimir a los cautivos', nos atenemos a la que recoge el Catecismo de la Iglesia Católica como 'Visitar a los presos'. CIC 2447.
} 

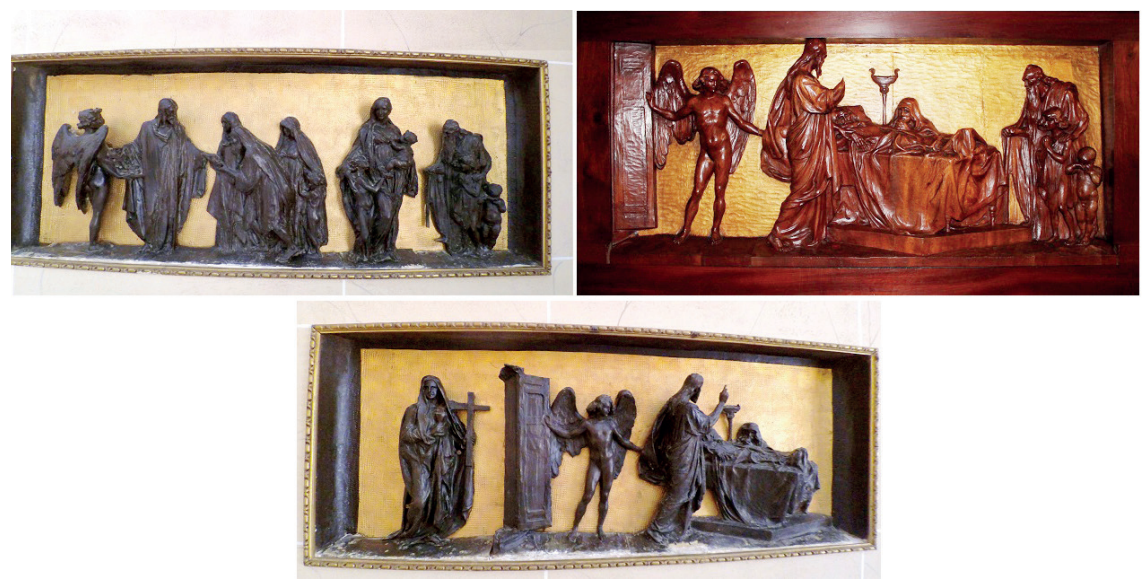

Figura 7. 'Dar de comer al hambriento', 'Caridad' y fragmento de 'Visitar a los enfermos'. Relieves en la Fundación Termens. Foto: José Lopera Muñoz. / 'Visitar a los enfermos'. Redención. Foto: Rafael Ángel García-Lozano. / 'Fe' y fragmento restante de 'Visitar a los enfermos'. Relieves en la Fundación Termens.

Foto: José Lopera Muñoz.

Atendiendo a la reorganización de las escenas en su definitiva estancia llegamos a la conclusión de que no faltan dos relieves correspondientes a paneles cortos, tal como asegura Guzmán (2002, pp. 102 y 106), sino un único panel correspondiente a un tramo largo. Quizás este recogiese en su emplazamiento original las tres virtudes teologales que la mesa de $R e-$ dención coloca en su paño frontal y que en la Fundación Termens han sido insertadas por separado con otros relieves ${ }^{4}$. En este caso, las Obras de misericordia representadas harían referencia todas ellas a las siete corporales y a ninguna de las espirituales, frente a la afirmación de Guzmán, que sostiene que se representan cinco corporales y dos espirituales, estas últimas 'Consolar al triste’ y 'Perdonar las injurias' (Guzmán, 2002, pp. 102 y 105). En cualquier caso, la mera identificación visual de las piezas de la Fundación Termens, ayudándonos de los paños de Redención, pone en evidencia que realmente los relieves consignados por Guzmán como 'Consolar al triste' y 'Perdonar las injurias' no son sino, respectiva e indudablemente, 'Visitar a los presos' y 'Visitar a los enfermos'.

${ }^{4}$ No obstante, Mariano Benlliure también podría haber optado por haber creado otra representación diferente para ese octavo fragmento (largo) del friso, lo cual le habría obligado a intercalar en este elemento arquitectónico las virtudes teologales con las Obras de misericordia -en caso de que las primeras estuvieran emplazadas en el friso-, o quizás haber incorporado alguna nueva obra de misericordia, espiritual en este caso, u otra representación adecuada al programa, si bien todo ello parece improbable. 
Asimismo, a tenor de la comparativa entre escenas, cabe señalar también que existen algunas diferencias entre el relieve 'Dar de comer al hambriento' del mausoleo, la cerámica del Museo Benlliure de Crevillente y la mesa de Redención, que son idénticos entre sí, y el mismo motivo fundido en bronce y que pertenecía a las puertas de entrada del salón de exposiciones de la residencia de Benlliure. Además del ángel existente en todos ellos, en este último la figura de Jesús entrega un pan a un anciano y a una mujer, mientras que aparece un niño bajo su mano izquierda, silueta esta última que en los paños del mausoleo, la cerámica y la mesa procesional se encuentra levemente más atrás, a la espalda de las dos figuras mencionadas y cobijada por una nueva figura incorporada de mujer (Fig.8), de modo que se compone de dos mujeres, un anciano y un niño, y no de tres mujeres como sostiene Guzmán (2002, p. 106). Este dato confirmaría que García Taléns talló los relieves de la mesa de Redención a partir de los bronces del mausoleo -o bien su modelo o copias- y no a partir del bronce de la casa de Benlliure, afirmación que quedaría corroborada además por la información que consta en los libros de la Fundición Codina, pues este último fue fundido en 1915, un año más tarde que los instalados en el panteón (Lucrecia Enseñat. Comunicación personal, 28 de enero, 2017).
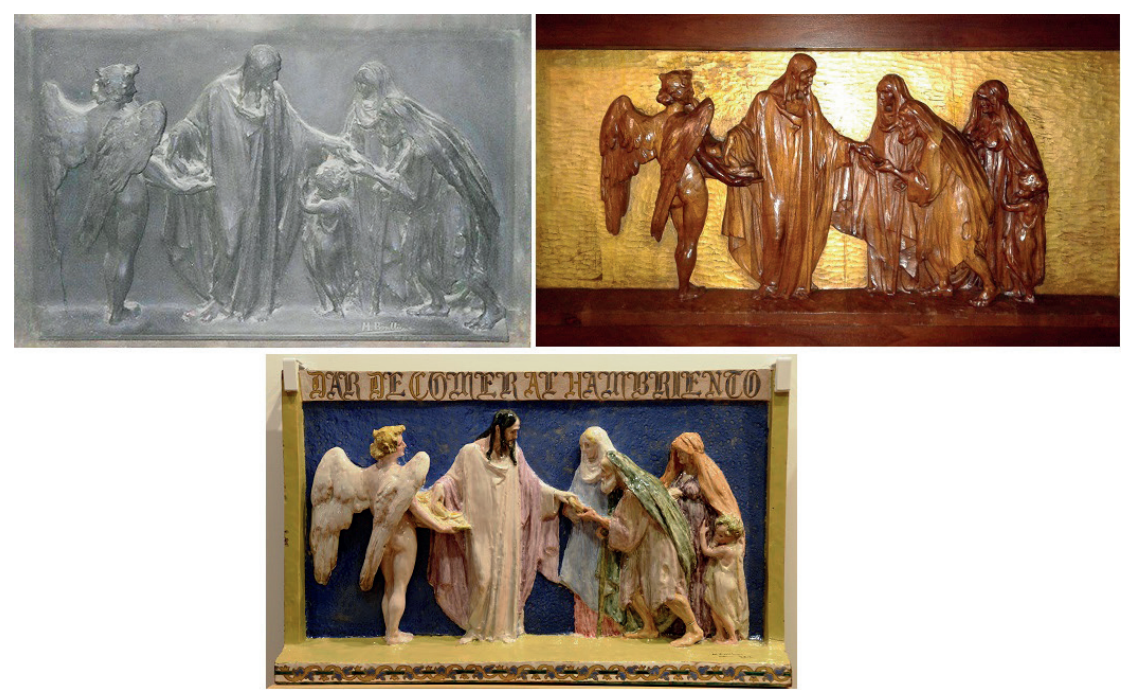

Figura 8. 'Dar de comer al hambriento'. Bronce procedente de la casa de Benlliure. Archivo Fundación Mariano Benlliure. / 'Dar de comer al hambriento'. Redención. Foto: Rafael Ángel García-Lozano. / 'Dar de comer al hambriento'. Cerámica policromada y vidriada. 74 x $38 \mathrm{~cm}$. Museo Benlliure. Crevillente. Foto: Archivo Fundación Mariano Benlliure. 
Asimismo, Guzmán comete un nuevo error en la enumeración de los personajes que aparecen en otras dos escenas. Respecto de la pieza 'Dar de beber al sediento, además de mencionar el ángel que siempre acompaña a Jesús, afirma que las "tres figuras de mujeres y un anciano se sitúan a un lado de la escena, en tanto que Cristo situado en el centro da de beber a una de ellas" (2002, p. 106), si bien realmente en el relieve aparecen dos figuras más. Una representa a una adolescente de temprana edad, desnuda, con las manos unidas en gesto de petición y amparada por la mujer mayor. Igualmente otra de las mujeres, en este caso la más joven y situada en el extremo izquierdo de la composición, porta un bebé en sus brazos. De este modo no hablaríamos ya de tres figuras de mujeres más un anciano, Cristo y el ángel (Guzmán, 2002, p. 106), sino de un total de ocho siluetas. Por su parte, en la escena 'Vestir al desnudo', junto a Jesucristo y el ángel que le asiste aparece efectivamente un anciano (Guzmán, 2002, p. 105), pero además este protege y cobija bajo sus brazos a un niño de baja estatura también desnudo (Fig. 9).

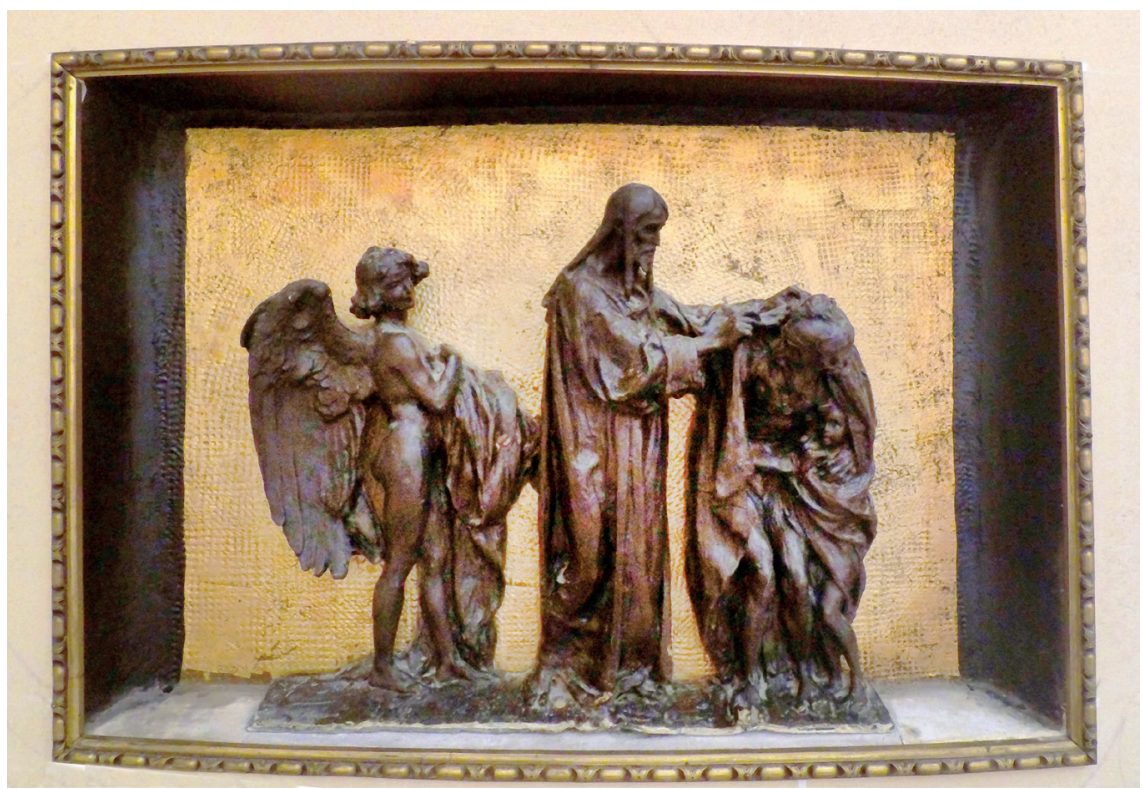

Figura 9. 'Vestir al desnudo'. Relieve en la Fundación Termens. Foto: José Lopera Muñoz. 
Cabe señalar que el anciano que aparece en las Obras de misericordia reproduce siempre el mismo modelo de hombre longevo, musculoso y con barba poblada, repitiéndose en todas las escenas con la excepción de 'Enterrar a los difuntos'. Seguramente Benlliure quiso contribuir de este modo a dotar de mayor unidad, si cabe, al conjunto. En todas las escenas el anciano es receptor principal de la obra de misericordia, salvo en 'Dar de beber al sediento', que no lo es directamente o bien es simple espectador, además de la referida 'Enterrar a los difuntos', cuyo personaje es, curiosamente, un barbilampiño joven. En 'Visitar a los enfermos' el anciano es, efectivamente, el que yace en cama y no la figura barbada que se encuentra en el extremo derecho de la composición.

También hemos de indicar que se evidencia alguna leve diferencia entre el panel 'Dar de beber al sediento' del mausoleo y el trabajado en la mesa de Redención. Efectivamente, García Taléns abigarró levemente la escena para que cupiera en el paño frontal trasero de la mesa del paso. De este modo el ala izquierda del ángel adopta una posición más vertical -menos desplegada que en el relieve metálico- y casi tocando el marco, mientras que en el extremo contrario el manto de la mujer más joven aparece parcialmente recortado a la izquierda. Igualmente el espacio existente entre el conjunto formado por la figura de Jesús y quien bebe del agua que él ofrece y el grupo de cinco figuras a su izquierda es sensiblemente menor en el paso que en el mausoleo (Fig. 10). En este punto llegamos a considerar la hipótesis de que esta escena fuera concebida por Benlliure como el resultado de la unión de dos agrupaciones independientes de personajes, una formada por las siluetas de Jesús, el ángel y la persona que bebe, y una segunda por las restantes cinco figuras. En este caso el primer grupo representaría propiamente y por sí solo la obra de misericordia y el segundo podría ser concebido como un grupo de relleno. De ser así, podríamos considerar que el segundo grupo podría relacionarse con alguna de las obras de misericordia espirituales y por tanto corresponder al panel largo desconocido. Quizá las más cercanas al motivo representado serían 'Enseñar al que no sabe,' 'Dar buen consejo al que lo necesita', 'Perdonar las injurias' o 'Consolar al triste'. Sin embargo, la ausencia de la figura de Jesús en la escena consigue abortar tal consideración, como también lo hace una cuestión meramente material, que no es otra que la unidad física del bronce como una única pieza, evidenciada por la continuidad de la representación del suelo en forma de forraje. No obstante, de existir otros bronces posteriores a 1914 podrían aportar algo de luz a esta cuestión, si bien por el momento no podemos despejar esta incógnita. 

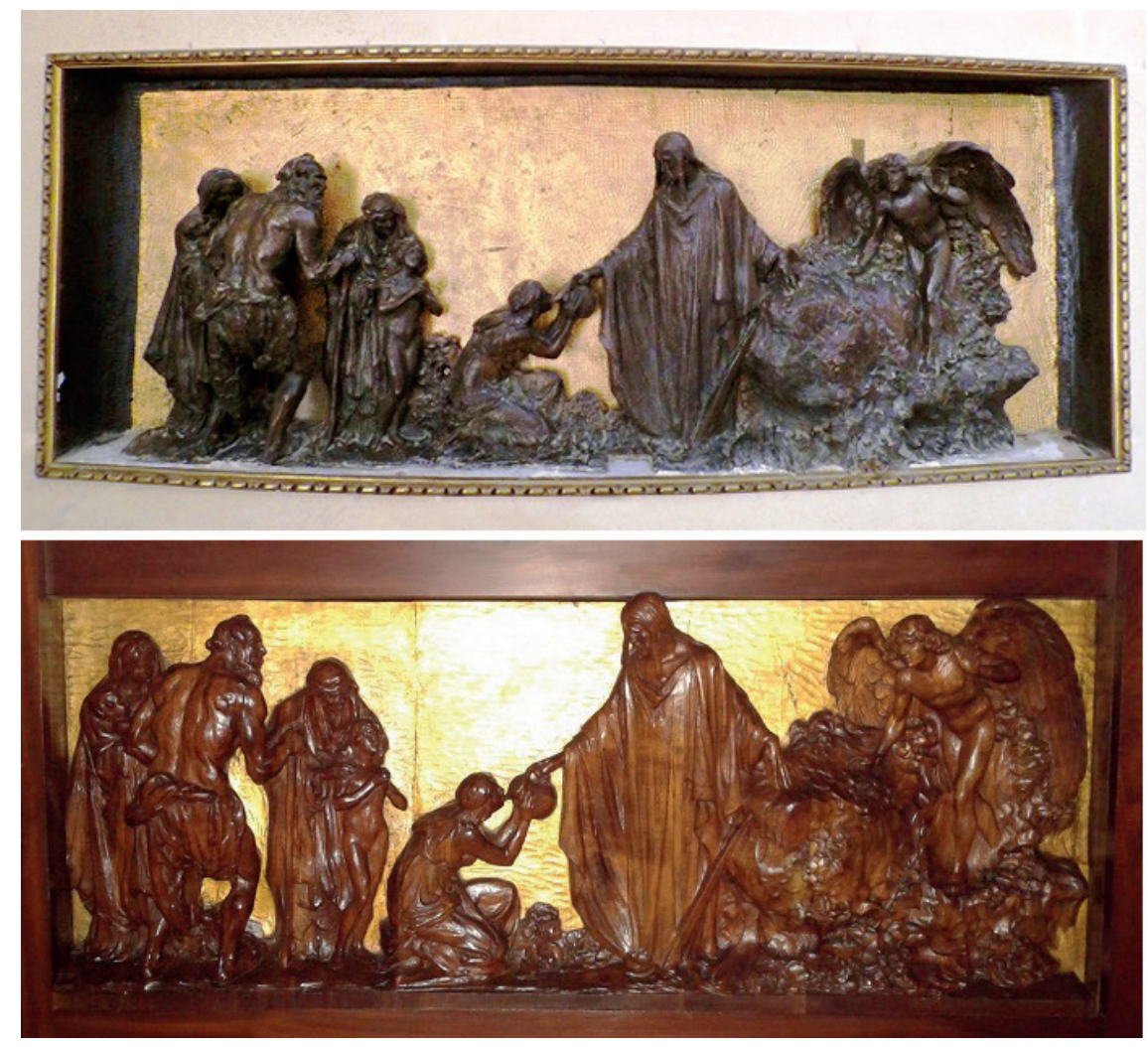

Figura 10. 'Dar de beber al sediento'. Relieve en la Fundación Termens. Foto: José Lopera Muñoz. / 'Dar de beber al sediento'. Redención. Foto: Rafael Ángel GarcíaLozano.

Sentadas estas cuestiones, resta indicar finalmente que, en los términos comparativos que hemos adoptado en nuestro análisis, el modelo escultórico de la imagen de Jesucristo que aparece representado en los bronces del mausoleo de la Vizcondesa y en sus copias o modelos constituye el paradigma más genuino de esta representación religiosa de Mariano Benlliure. Se ha señalado que los precedentes de la figura de Cristo de Redención se hallan en la estatua marmórea de la capilla del Sagrado Corazón de Jesús de la iglesia de San Ignacio en San Sebastián, realizada por Benlliure en 1913 (Casquero, 2009, p. 25). Sin embargo, atendiendo a la imagen principal de Redención consideramos que el tratamiento fundamentalmente de la túnica-francamente distante de la donostiarra-, la ejecución más contundente de los payot (tirabuzones) de Cristo y la propia solemnidad de la imagen, 
con ser muy semejantes, se ajustan más directamente al modelo representado en las Obras de misericordia que a la estatua guipuzcoana.

\section{REFERENCIAS}

Casquero, J. A. (2003). Apuntes históricos sobre el paso Redención. Zamora: Cofradía de Jesús Nazareno.

Casquero, J. A. (2004). El paso de Jesús Descendido y la imaginería religiosa y procesional de Mariano Benlliure. Zamora: Fundación Caja Rural-Cofradía del Santo Entierro.

Casquero, J. A. (2009). Pasos e imágenes de La Congregación: la imaginería procesional de la Cofradía de Jesús Nazareno en Zamora. Zamora: Cofradía de Jesús Nazareno de Zamora.

Casquero, J. A. (2012). La imaginería procesional de la Semana Santa en la Diócesis de Zamora. En J. Aranda (ed.). Cofradías penitenciales y Semana Santa. Actas (pp. 311-69). Córdoba, España: Diputación de Córdoba.

Dirección General de Patrimonio Histórico, Comunidad de Madrid y Consorci de Museus de la Comunitat Valenciana. (2013). Mariano Benlliure. El dominio de la materia. Madrid: Comunidad de Madrid.

Enseñat, L. (2018). Panorámica de la escultura religiosa de Mariano Benlliure anterior a la guerra del 36. En A. Satorre (coord.). Crevillent: escultura religiosa, MUBAG y Museo M. Benlliure (pp. 45-65). Crevillet: Ayuntamiento de Crevillent.

Fernández-Prieto, E. y García, P. (1997). Semana Santa de Zamora. Crónica de cien años. Zamora: El Norte de Castilla.

García, J. (2014). Benlliure, el dominio de la materia. Barandales, 21, 24-28.

García-Lozano, R. Á. (2008). El Museo de Semana Santa de Zamora. Antecedentes, proyecto y realización. Anuario del Instituto de Estudios Zamoranos Florián de Ocampo, 25, 93-132.

García-Lozano, R. Á. (2010). El hospital y la capilla de la Cofradía de los Ciento. Aportaciones para el estudio del urbanismo y la arquitectura de Zamora. Studia Zamorensia, 9, 35-86.

García-Lozano, R. Á. (2011). La panera de La Congregación. Barandales, 19, 84-7.

Guzmán, S. (2002). El Mausoleo de la Vizcondesa de Termens de Cabra. Córdoba: Diputación de Córdoba.

Guzmán, S. (2010). La Infantona. Rival de la Infanta Eulalia: Carmela Giménez, Vizcondesa de Termens. Madrid: Áltera.

Méndez Casal, A. (1931, 2 de abril). El nuevo paso procesional de la basílica zamorana. $A B C$, pp. 15-17.

Miranda, L. (2011, 26 de febrero). La Infantona no fue una nueva rica; se distinguió por su creatividad. $A B C$. Recuperado de https://sevilla.abc.es/ 
20110226/cordoba/sevi-infantona-nueva-rica-distinguio-201102260847. html

Quevedo, C. (1947). Vida artística de Mariano Benlliure. Madrid: Espasa Calpe. Sambricio, C., Portela, F. y Torralba, F. (1989). Historia del arte hispánico. Siglo $X X$. Madrid: Alhambra. 